\title{
Clinical Features and Treatment of Fibrous Histiocytomas of the Tongue: A Systematic Review
}

\author{
Austin Nguyen ${ }^{1} \quad$ Adam Vaudreuil $^{1} \quad$ Paul Haun $^{2}$ Gabriel Caponetti ${ }^{2}$ Christopher Huerter ${ }^{1}$ \\ ${ }^{1}$ Division of Dermatology, Creighton University School of Medicine, \\ Omaha, Nebraska, United States \\ 2 Department of Pathology and Laboratory Medicine, University of \\ Pennsylvania Perelman School of Medicine, Philadelphia, \\ Pennsylvania, United States \\ Address for correspondence Austin Nguyen, MS, Division of \\ Dermatology, Creighton University School of Medicine, 2500 \\ California Plaza, Omaha, NE 68178, United States \\ (e-mail: ahn30605@creighton.edu).
}

Int Arch Otorhinolaryngol 2018;22:94-102.

\begin{abstract}
Introduction Benign fibrous histiocytomas are common lesions of the skin that rarely affect the tongue. Such cases are available in the literature exclusively as case reports. Similarly, malignant fibrous histiocytoma, now classified as undifferentiated pleomorphic sarcoma, is exceedingly rare in the tongue and not fully understood.

Objectives This study systematically reviews the available literature discussing the clinical and pathological features of malignant and benign fibrous histiocytomas.

Data Synthesis A total of 20 cases were included in this review. Patient-level data were extracted from cases to include clinical presentation, workup, treatment, and outcome.
Keywords
- dermatofibrosarcoma
- dermatofibroma
- fibrous histiocytoma
- tongue neoplasm

Conclusion Benign fibrous histiocytomas are consistent in clinical and histopathologic presentation. Surgical treatment provides excellent outcome, with no recurrence in all excised cases. Malignant tumors have a more aggressive clinical and pathological presentation. Surgical treatment with possible adjuvant radiotherapy resulted in recurrence in $40 \%$ of cases (follow-up of 24 months), and death due to disease in $47 \%$ of patients (follow-up of 19 months).
\end{abstract}

\section{Introduction}

Fibrous histiocytomas can be classified as benign and malignant. Benign fibrous histiocytomas (BFHs) can be further sub-divided by tissue of origin, either dermal or deep (subcutaneous). Cutaneous benign fibrous histiocytoma, or dermatofibroma, is localized to the dermis and characterized by an assortment of spindle and/or rounded cells. ${ }^{1}$ It is a common lesion seen in many age groups, with predominance in the 3rd and 4th decades of life, and gender distribution varying by population. ${ }^{1}$ The majority of lesions are found on the extremities, with lesions rarely arising on the face. ${ }^{1}$ Clinically, BFHs present as single, round lesions, appearing

received

October 31, 2016

accepted

March 9, 2017

published online

May 2, 2017

10.1055/s-0037-1602819.

ISSN 1809-9777. reddish early on, and transitioning to more brown or skincolored with time. They are moderately well circumscribed, and produce the characteristic "dimpling" sign when squeezed between the examiners fingers. ${ }^{1}$ Benign fibrous histiocytomas have a variable immunohistochemical profile and multiple histologic subtypes: aneurysmal, epithelioid, cellular, angiomatoid, etc. These lesions are considered benign, and tend to recur only with incomplete excision. ${ }^{1}$ Deep BFHs generally involve subcutaneous tissue, and affects adults over 25 years, with a mean age of 40 years. ${ }^{2,3}$ Similar to BFHs, the majority of deep BFHs are on the extremities, but may also occur in the head and neck region. ${ }^{2}$ Clinically, deep $\mathrm{BFH}$ lesions are seen as painless, slowly enlarging masses,

Copyright @ 2018 by Thieme Revinter

Publicações Ltda, Rio de Janeiro, Brazil

License terms

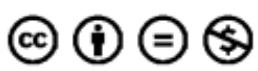


and are more well circumscribed/encapsulated than the cutaneous form. ${ }^{2}$ Metastasis has yet to be reported.

Malignant fibrous histiocytoma (MFH) was first described by O'Brien and Stout in $1964 .{ }^{4}$ Malignant fibrous histiocytoma was historically thought to be the malignant and undifferentiated counterpart of the BFH. Recent advances have changed our understanding of their cell origin, resulting in reclassification as undifferentiated pleomorphic sarcoma. However, many clinicians continue to use the broader term MFH. In adults, MFH is the second most common soft tissue sarcoma (STS), with an incidence of 0.88 cases per 100,000 annually. $^{5}$ It occurs more commonly in men $(2: 1$, Male: Female), and the incidence increases with age. ${ }^{5,6}$ Malignant fibrous histiocytoma is one of the most commonly diagnosed sarcomas in patients with prior radiation exposure in the head or neck region. ${ }^{7}$ The most common locations of these tumors in order are the head and neck, the extremities, the trunk, and the retroperitoneum. ${ }^{8}$ Those occurring on the head and neck might exhibit a more aggressive course; one study reported a 5-year overall survival of $48 \%$ for patients with head and neck tumors compared with $77 \%$ for patients with trunk or extremity tumors. ${ }^{9}$

The clinical presentation typically involves a painless, enlarging nodule that can become painful if enlarging rapidly. ${ }^{8}$ Identification often involves histologic and immunohistochemical evaluations. Treatment typically involves wide local excision, en bloc resection with $2 \mathrm{~cm}$ margins of uninvolved tissue, or Mohs surgery. ${ }^{8,10}$ However, local recurrence rates are high, ranging from 25 to $75 \% .^{5,8}$ Additional treatment with adjuvant radio- or chemotherapy should be considered on an individual case basis. ${ }^{11}$

Malignant or benign fibrous histiocytoma involvement of the tongue is considerably rare, and offers additional symptomatology, such as difficulty speaking or swallowing. ${ }^{12,13}$ Our review of the available literature identified 20 published cases. Thus, the present review serves to comprehensively describe previously published cases of BFH and MFH involving the tongue and aggregate information involving the rare presentation of this tumor entity.

\section{Review of the Literature}

\section{Literature Search}

The National Library of Medicine PubMed database was searched for articles discussing dermatofibromas and dermatofibrosarcomas, or fibrous histiocytomas affecting the tongue. The following search terms were used: tongue and lingual combined with undifferentiated pleomorphic sarcoma, dermatofibroma, fibrous histiocytoma, and dermatofibrosarcoma. The articles were screened for relevance based on title and abstract. Potentially relevant articles were subsequently reviewed in full-text for final inclusion decision. Additionally, the references of each included article were screened for additional potentially relevant articles. Potentially relevant articles were case reports or case series or studies discussing fibrous histiocytomas affecting the tongue that described patient-level data and met the inclusion criteria. The inclusion criteria were: articles discussing the clinical course of cases of lingual fibrous histiocytoma, including presentation, diagnostic workup, treatment, and outcome. Articles were excluded if they did not contain patient-level data and/or original data (that is, literature reviews), did not pertain to the present topic, or were published in a language other than English. Of the included articles, patient-level data was extracted and discussed in the present review.

The search of the PubMed database through September 2016 (-Fig. 1) returned 234 articles. Screening by title and abstract left 18 potentially relevant articles for full-text review. Upon full-text review, two studies were excluded for having diagnoses that did not meet the inclusion criteria (that is, a diagnosis other than fibrous histiocytoma). Two additional articles were found to meet the inclusion criteria upon the screening of the article citations. Ultimately, a group of 18 articles, describing 20 cases, was included in this review. These cases included 15 malignant ${ }^{12,14-25}$ and 5 benign ${ }^{13,26-29}$ fibrous histiocytomas affecting the tongue.

\section{Clinical Presentation}

The demographic profiles of fibrous histiocytomas, summarized in -Table 1, were markedly different between the benign and malignant tumors. The mean patient age for BFH was 25.8 (range, 8-51) years, whereas MFH appears to affect an older population, with a mean age of 46.6 (range, 0.4-72) years. Additionally, the benign form reportedly had a marked predilection for females, with $80.0 \%$ of cases involving female patients versus $40.0 \%$ of cases involving female patients in the malignant form.

The cases generally presented as a gradually progressive, painless nodule on the tongue with a firm and/or rubbery, elastic texture. The benign cases demonstrated no overt epithelial disruption. The malignant tumors were slightly larger than the benign ones, with an average diameter of $2.92 \mathrm{~cm}$ and $2.48 \mathrm{~cm}$ respectively. The malignant cases often presented as gray/white, ulcerated, or fungating lesions $(n=8 ; 53.3 \%)$ that may have affected tongue movement ( $n=2 ; 13.3 \%)$. Single cases reported physiologic effects of the tumor, such as dysphagia, hoarseness, and sore throat. Cervical lymphadenopathy was not reported in any benign or malignant cases. However, constitutional symptoms such as weight loss and fever were reported in single cases. The duration of the symptoms was 3.6 (range, 0-12) months on average for the malignant cases. Benign cases presented later, at 5.0 (range, 2-7) months.

\section{Workup}

Blood chemistry values were rarely reported and otherwise generally unremarkable. Diagnostic imaging studies were reported in two malignant cases, and minimally discussed. The diagnosis was made with histopathologic evaluation in all cases. Tissue was usually procured through excisional or incisional biopsy, though one case employed the use of fine needle aspiration (FNA). Histopathological evaluation was the primary diagnostic modality; the most commonly observed histopathologic features are summarized in - Table 2. On the histopathologic evaluation (-Fig.2), BFH lesions were predominantly composed of plump spindle-shaped fibroblasts arranged in a storiform pattern. Scattered histiocytes 


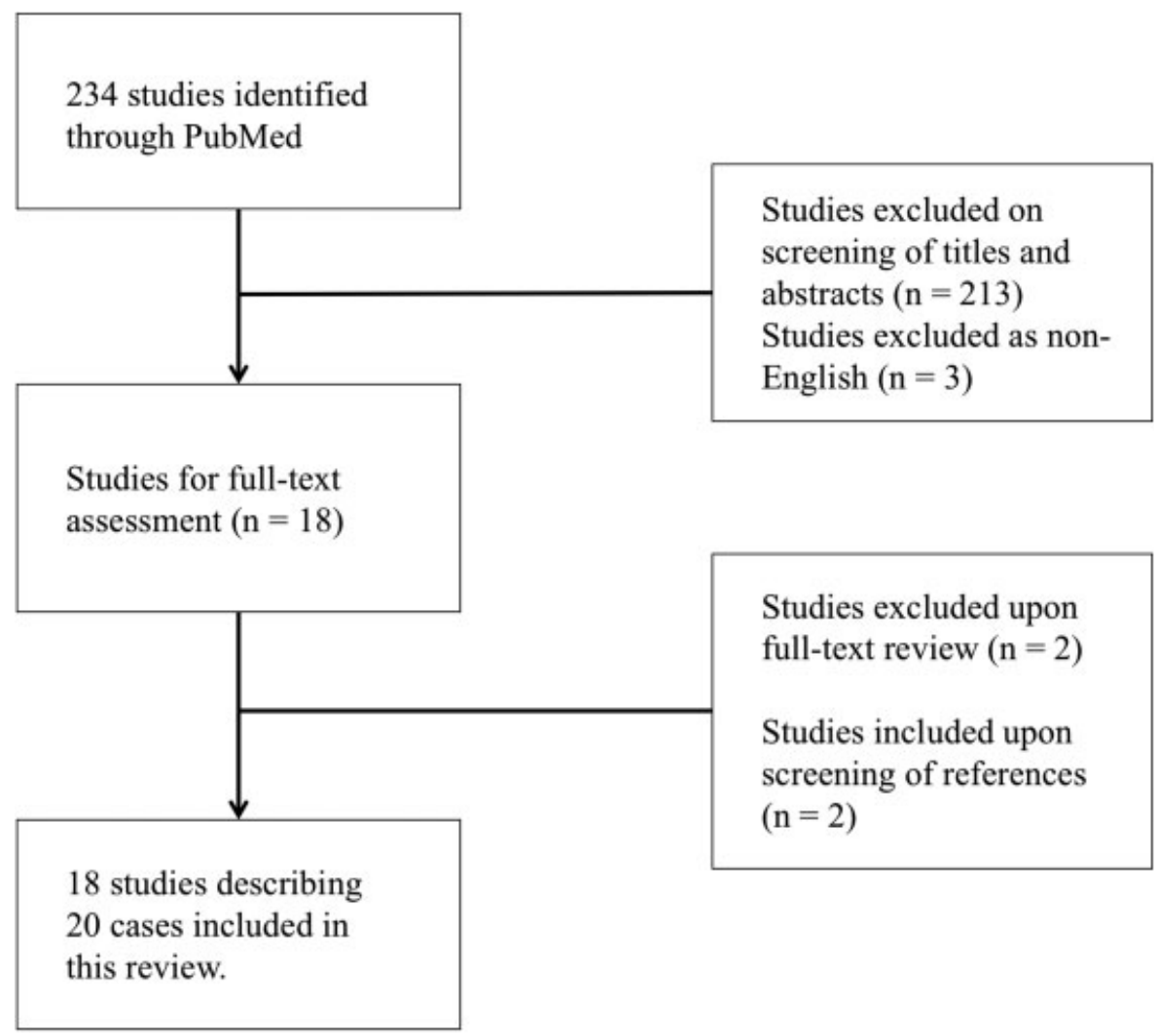

Fig. 1 Systematic search and review strategy of the PubMed database. The initial search returned 234 articles. After screening the titles and abstracts, 18 articles were reviewed in full-text for final inclusion. Of these, two articles were excluded for not meeting the inclusion criteria. Two additional articles were included after screening the references of the included cases. A final group of 18 articles describing 20 cases was included in this review.

were present and demonstrated pale and/or round nuclei, though occasional mitotic figures were present in two cases. The MFH cases exhibited pleomorphic cells that were haphazardly arranged with occasional storiform foci. Mitotic figures were present in the majority of cases $(n=8$ of 13 , $61.5 \%$ ). The spindle-shaped fibroblasts cells were reported to have ovoid, elongated nuclei with dense clumped chromatin. The histiocyte-like cells were hyperchromatic with lobulated nuclei and a granular or foamy cytoplasm. Multinucleated giant cells were present in 8 cases (61.5\%), and exhibited pleomorphic nuclei.

The immunohistochemistry results (summarized in -Table 2) were reported in 4/5 BFH and in 6/15 MFH cases, and were primarily valuable for diagnostic exclusion. The reported immunostains were as follows: $\alpha 1$-antitrypsin, $\alpha 1$-antichymotrypsin, CD117, CD31, CD34, CD68, carcinoembryonic antigen (CEA), cytokeratin, desmin, factor VIII, keratin, $\mathrm{K}_{\mathrm{i}}-67$ protein, Leu7, S100, smooth muscle actin, and vimentin. One to two malignant and benign cases were reported to have $\alpha 1$-antitrypsin, $\alpha 1$-antichymothrypsin, CD34, CD68, smooth muscle actin, and vimentin immunoreactivity. Benign and malignant cases were both consistently negative for desmin and S100 staining.

\section{Treatment and Outcome}

The treatment and outcomes of the included cases are summarized in $\mathbf{- T a b l e ~} \mathbf{3}$. All BFHs were treated surgically with local excision $(n=4,80.0 \%)$ or $\mathrm{CO}_{2}$ laser excision $(n=1,20 \%)$. The single recurrent case, initially excised with $\mathrm{CO}_{2}$ laser, was treated with subsequent hemiglossectomy. No cases of benign tumors received radiation or chemotherapy. At an average follow-up of 44.6 months, all benign cases were reported to be disease free.

Malignant tumors were primarily treated with surgery. Resection/excision was performed in 4 cases ( $n=4 ; 26.7 \%$ ). Partial or hemiglossectomy was performed in 6 cases $(n=6$; $40.0 \%)$; Total glossectomy was performed in 1 case $(n=1$; $6.7 \%)$. Neck dissection was performed in 4 (26.7\%) cases to evaluate the cervical lymph nodes for possible metastasis. Adjuvant radiotherapy was administered in 8 (53.3\%) cases, often for recurrent disease or for suspicion of metastasis, with various modalities: iridium or radium implant/brachytherapy, telecobalt therapy, or unspecified external beam radiotherapy, and the results varied. Adjuvant chemotherapy was administered in $4(26.7 \%)$ cases, also often for recurrence or metastasis. Combination chemotherapy regimens included doxorubicin + dacarbazine, actinomycin D + vincristine sulfate + cyclophosphamide, or cyclophosphamide + vincristine + doxorubicin + dacarbazine (CYVADIC). Recurrence occurred in $6(40.0 \%)$ cases. At an average follow-up of 24.1 (range, 9-37) months, 8 (53.3\%) cases were disease-free. In 7 (46.6\%) cases, the patients succumbed to disease at an average of 19 (range, 9-34) months. All cases are summarized in -Table 4 . 
Table 1 Patient Demographics and Clinical Presentation of Fibrous Histiocytoma of the Tongue

\begin{tabular}{|c|c|c|}
\hline Characteristic & $\begin{array}{l}\text { Benign Fibrous } \\
\text { Histiocytoma, n (\%) }\end{array}$ & $\begin{array}{l}\text { Malignant Fibrous } \\
\text { Histiocytoma, n (\%) }\end{array}$ \\
\hline \multicolumn{3}{|l|}{ Demographics } \\
\hline Mean, range of age (years) & $25.8,8-51$ & $46.6,0.4-72$ \\
\hline Female & $4(80.0)$ & $8(40.0)$ \\
\hline Male & $1(20.0)$ & $9(60.0)$ \\
\hline \multicolumn{3}{|l|}{ Presentation } \\
\hline Mean, range of tumor diameter $(\mathrm{cm})$ & $2.5,0.4-5.5$ & $2.9,1-5.6$ \\
\hline Duration of symptoms (months) & 5.0 & 3.6 \\
\hline Painful* & $0(0.0)$ & $2(13.3)$ \\
\hline Firm* & $4(80.0)$ & $2(13.3)$ \\
\hline $\begin{array}{l}\text { Epithelial disruption } \\
\text { (gray/white, ulcerated, fungating)* }\end{array}$ & $0(0.0)$ & $8(53.3)$ \\
\hline \multicolumn{3}{|l|}{ Location } \\
\hline Anterior & $1(20.0)$ & $2(13.3)$ \\
\hline Posterior & $0(0.0)$ & $3(20.0)$ \\
\hline Left lateral & $2(40.0)$ & $6(40.0)$ \\
\hline Right lateral & $1(20.0)$ & $3(20.0)$ \\
\hline Base & $1(20.0)$ & $2(13.3)$ \\
\hline Dorsal & $2(40.0)$ & $3(20.0)$ \\
\hline Ventral & $1(20.0)$ & $0(0.0)$ \\
\hline Unspecified & $0(0.0)$ & $2(13.3)$ \\
\hline
\end{tabular}

Notes: *Presence/absence of each finding not reported in all cases. Percent is out of total number of cases. Total benign fibrous histiocytoma cases: $n=5$. Total malignant fibrous histiocytoma cases: $n=15$.

Table 2 Histologic characteristics of fibrous histiocytoma of the tongue

\begin{tabular}{|l|l|l|}
\hline Characteristic & $\begin{array}{l}\text { Benign Fibrous } \\
\text { Histiocytoma, n (\%) }\end{array}$ & $\begin{array}{l}\text { Malignant Fibrous } \\
\text { Histiocytoma, } \mathbf{n}(\%)\end{array}$ \\
\hline Histologic finding* & $2(40.0)$ & $8(61.5)$ \\
\hline Pleomorphic & $2(40.0)$ & $8(61.5)$ \\
\hline Mitotic figures & $3(60.0)$ & $10(76.9)$ \\
\hline Storiform pattern & $5(100.0)$ & $13(100.0)$ \\
\hline Spindle, fibroblast-like cells & $5(100.0)$ & $12(92.3)$ \\
\hline Histiocyte-like cells & $0(0.0)$ & $8(61.5)$ \\
\hline Multinucleated giant cells & $4(100.0)^{\dagger}$ & $6(100.0)^{\dagger}$ \\
\hline Immunohistochemical expression & $1(25.0)$ & $2(33.3)$ \\
\hline Q-chymotrypsin & $2(50.0)$ & $0(0.0)$ \\
\hline CD34 & $0(0.0)$ & $0(0.0)$ \\
\hline Cytokeratin & $0(0.0)$ & $0(0.0)$ \\
\hline Desmin & $0(0.0)$ & $0(0.0)$ \\
\hline Keratin & $0(0.0)$ & $0(0.0)$ \\
\hline S100 & $2(50.0)$ & $1(16.7)$ \\
\hline Vimentin & & \\
\hline
\end{tabular}

Notes: *Malignant fibrous histiocytoma histologic findings are shown as percent out of 13 cases with available histologic data. ${ }^{\dagger}$ Immunostain not reported in all cases. Percent positivity is out of the total number of cases with immunostain data available. 
98 Lingual Fibrous Histiocytoma Nguyen et al.
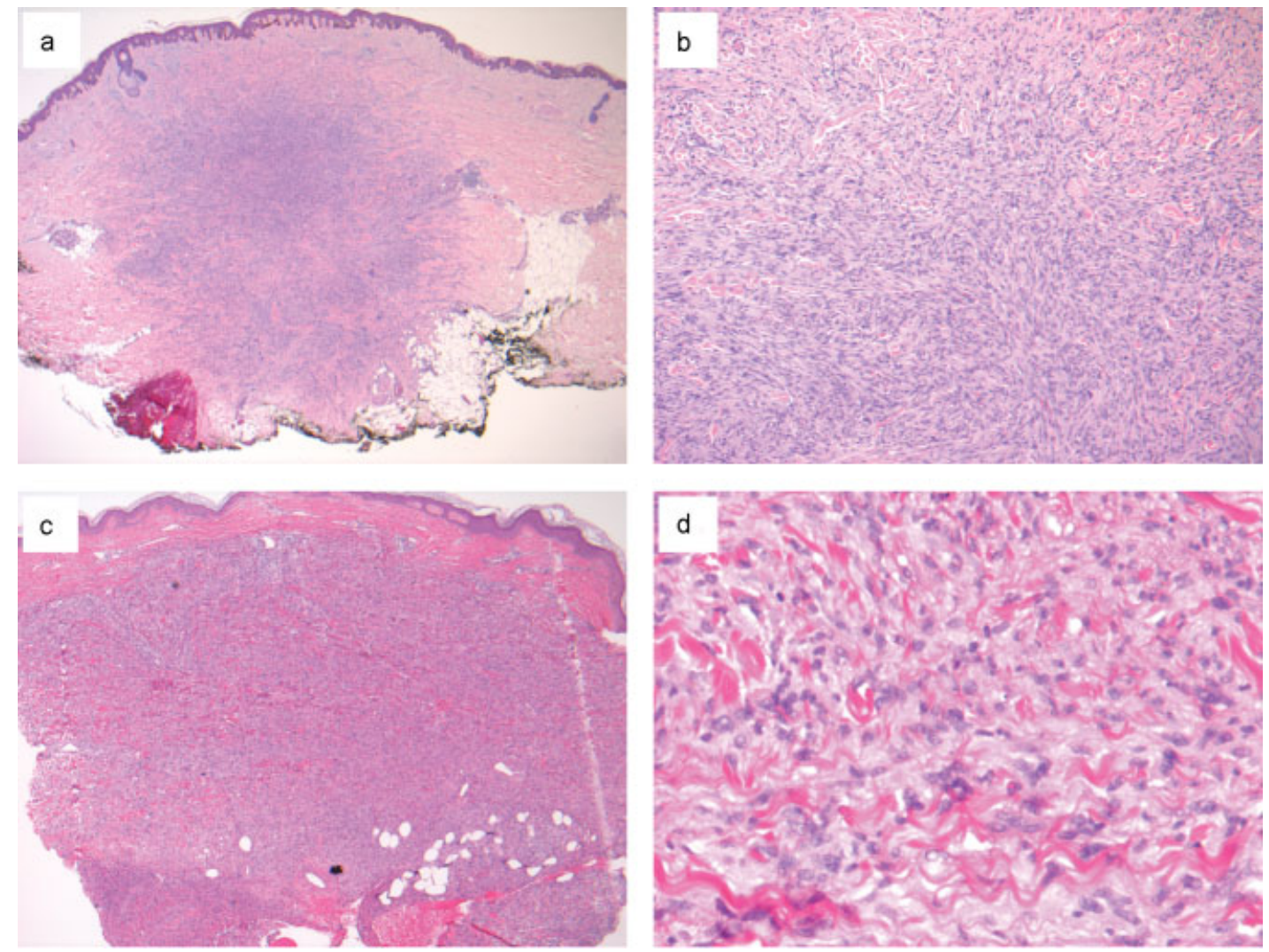

Fig. 2 Benign fibrous histiocytoma histology (a-b) showing spindle-shaped fibroblasts arranged in a storiform pattern with scattered histiocytes. Malignant fibrous histiocytoma histology (c-d) demonstrates spindle-shaped to pleomorphic cells haphazardly arranged with occasional mitotic figures (Courtesy of Dr. Paul L. Haun, M.D.).

Table 3 Treatment and Outcome of Fibrous Histiocytoma of the Tongue

\begin{tabular}{|c|c|c|}
\hline & $\begin{array}{l}\text { Benign Fibrous } \\
\text { Histiocytoma, n (\%) }\end{array}$ & $\begin{array}{l}\text { Malignant Fibrous } \\
\text { Histiocytoma, n (\%) }\end{array}$ \\
\hline \multicolumn{3}{|l|}{ Treatment } \\
\hline Resection/excision & $4(80.0)$ & $4(26.7)$ \\
\hline Partial/hemiglossectomy & $1(20.0)$ & $6(40.0)$ \\
\hline Total glossectomy & $0(0.0)$ & $1(6.7)$ \\
\hline Neck dissection & $0(0.0)$ & $4(26.7)$ \\
\hline Chemotherapy & $0(0.0)$ & $4(26.7)$ \\
\hline Radiotherapy & $0(0.0)$ & $8(53.3)$ \\
\hline $\mathrm{CO}_{2}$ laser excision/debulking & $1(20.0)$ & $2(13.3)$ \\
\hline \multicolumn{3}{|l|}{ Outcomes } \\
\hline Recurrence & $1(20.0)$ & $6(40.0)$ \\
\hline Disease free & $5(100.0)$ & $8(53.3)$ \\
\hline Death due to the disease & $0(0.0)$ & $7(46.6)$ \\
\hline Mean, range of follow-up (months) & $44.6,1-144$ & $21.7,9-37$ \\
\hline
\end{tabular}

Notes: Percent may add up to more than 100 due to patients receiving multiple treatment modalities. Reported case numbers ( $\mathrm{n}$ ) may add up to more than the total number of cases $(\mathrm{BFH}=5 ; \mathrm{MFH}=15)$ due to patients receiving multiple treatment modalities. 


\begin{tabular}{|c|c|c|c|c|c|c|c|c|c|c|c|c|}
\hline 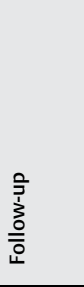 & 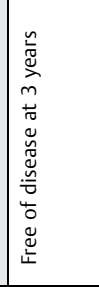 & 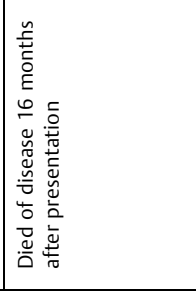 & 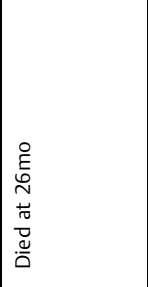 & 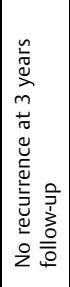 & 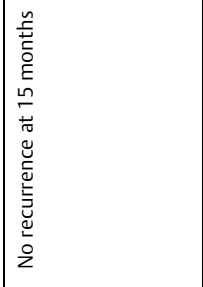 & 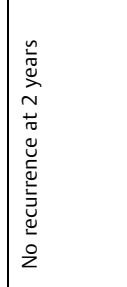 & 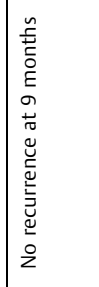 & 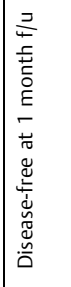 & 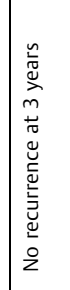 & 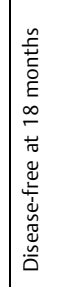 & 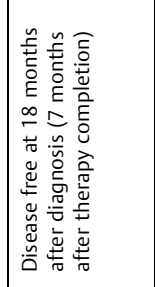 & 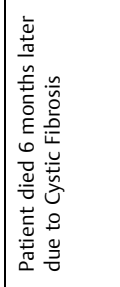 \\
\hline $\begin{array}{l}\frac{y}{\bar{z}} \\
\stackrel{\bar{u}}{\simeq}\end{array}$ & 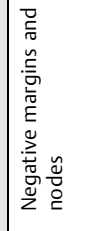 & 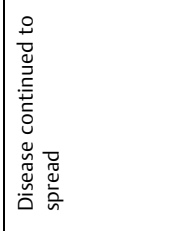 & 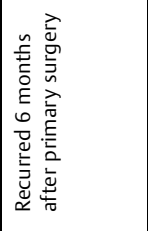 & 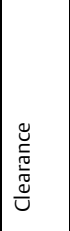 & 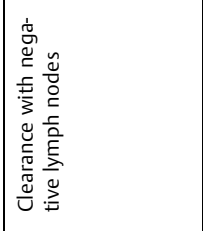 & & & & 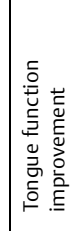 & & 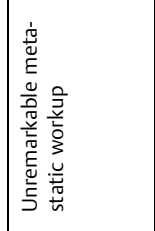 & 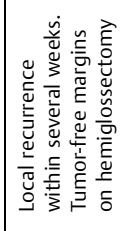 \\
\hline 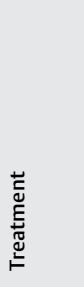 & 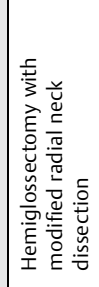 & 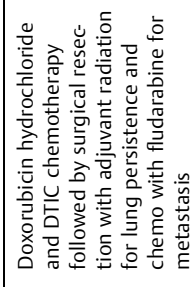 & 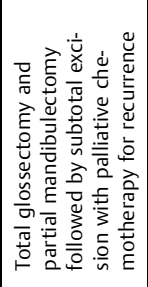 & 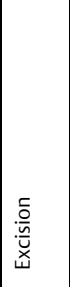 & 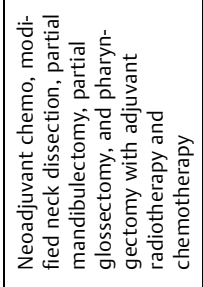 & 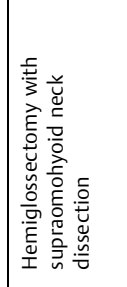 & 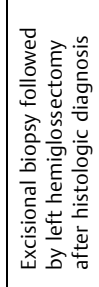 & 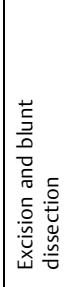 & 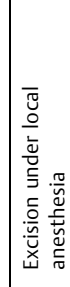 & 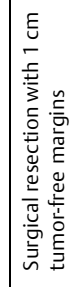 & 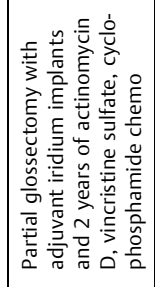 & 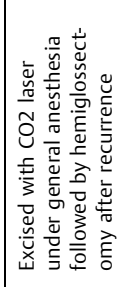 \\
\hline 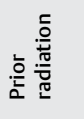 & $\frac{\mathscr{0}}{\tilde{c}}$ & 总 & 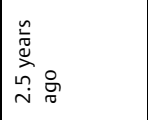 & 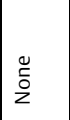 & $\begin{array}{l}0 \\
\tilde{5} \\
2\end{array}$ & 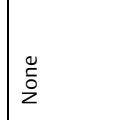 & \begin{tabular}{|l}
0 \\
$\tilde{c}$ \\
2
\end{tabular} & \begin{tabular}{|l}
0 \\
$\tilde{\tilde{c}}$ \\
2
\end{tabular} & 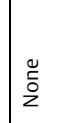 & 蒿 & 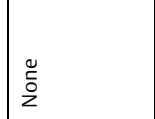 & 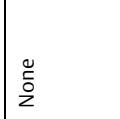 \\
\hline 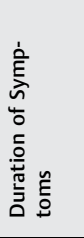 & $\begin{array}{l}\text { 竭 } \\
\text { in }\end{array}$ & 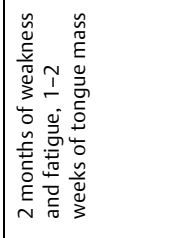 & 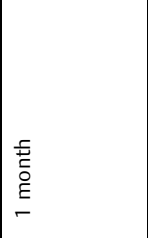 & 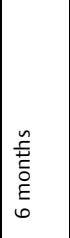 & 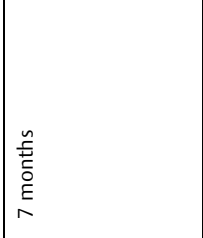 & 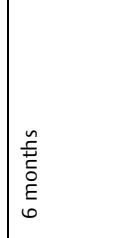 & 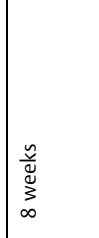 & 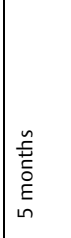 & 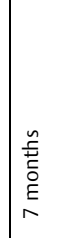 & 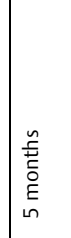 & & 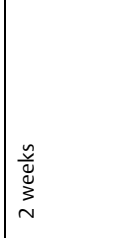 \\
\hline 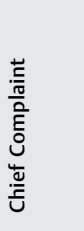 & 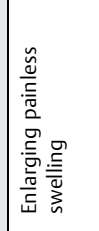 & 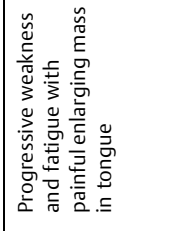 & 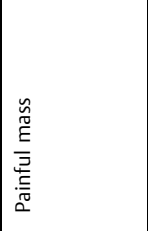 & 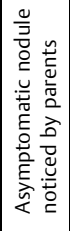 & 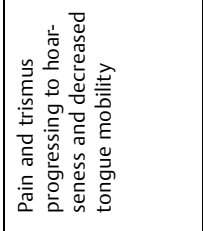 & 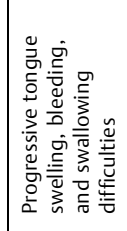 & 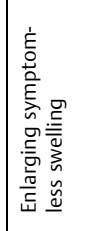 & 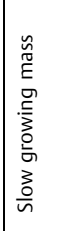 & 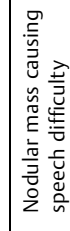 & 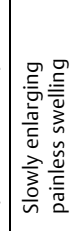 & 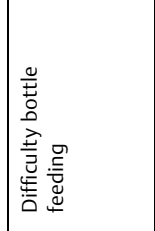 & 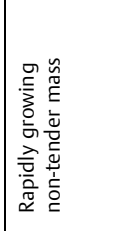 \\
\hline$\stackrel{\Sigma}{\tilde{n}}$ & $\begin{array}{l}\underset{\mathrm{U}}{\mathrm{N}} \\
\stackrel{\mathrm{N}}{\mathrm{X}} \\
\mathrm{X}\end{array}$ & 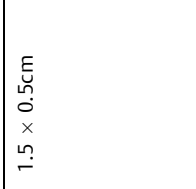 & 1 & $\begin{array}{l}E \\
E \\
\vdots \\
0 \\
x \\
x \\
\dot{0} \\
0\end{array}$ & 1 & \begin{tabular}{|l}
$E$ \\
$E$ \\
$\sim$ \\
$x$ \\
$n$ \\
$x$ \\
$\sigma$ \\
$\sigma$
\end{tabular} & 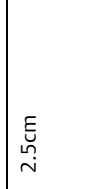 & \begin{tabular}{|l}
$E$ \\
E \\
$\times$ \\
$\times$ \\
0
\end{tabular} & $\begin{array}{l}\underset{\mathrm{m}}{E} \\
\times \\
\mathrm{m}\end{array}$ & $\begin{array}{l}E \\
\underline{\sigma} \\
x \\
\sim \\
x \\
m\end{array}$ & 1 & \begin{tabular}{|l}
$E$ \\
$E$ \\
$\hat{0}$ \\
$x$ \\
$x$ \\
$N$ \\
$x$ \\
$N$ \\
$\tilde{m}$
\end{tabular} \\
\hline 高 & $\frac{I}{\Sigma}$ & 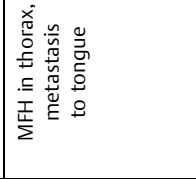 & $\frac{I}{\Sigma}$ & 志 & 至 & 采 & 寽 & 杢 & 嗯 & 寽 & 王 & 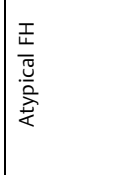 \\
\hline 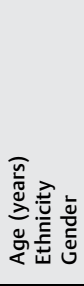 & 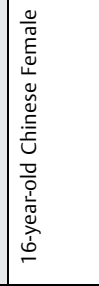 & 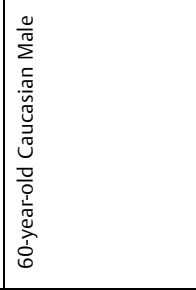 & 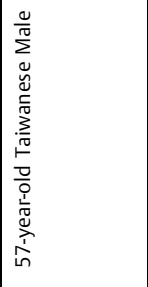 & 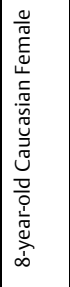 & 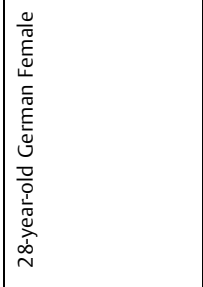 & 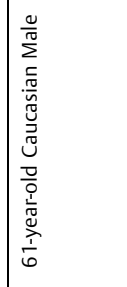 & 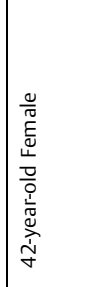 & 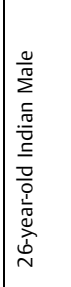 & 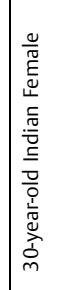 & 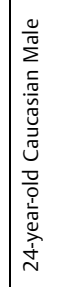 & 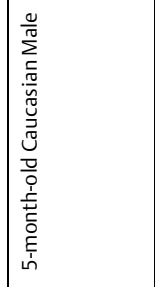 & 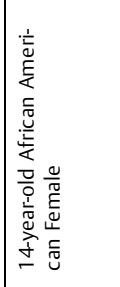 \\
\hline 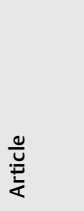 & 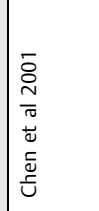 & 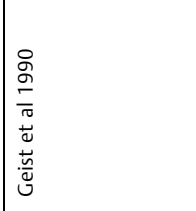 & 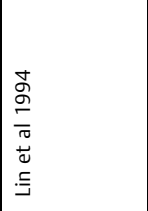 & 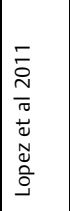 & 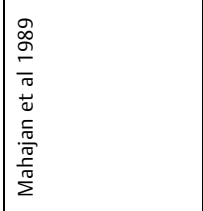 & 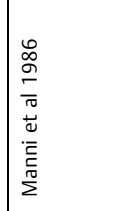 & 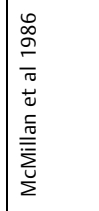 & 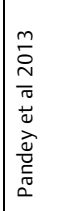 & 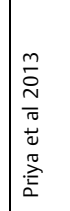 & 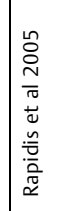 & 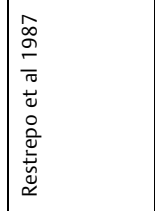 & 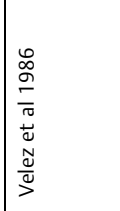 \\
\hline
\end{tabular}




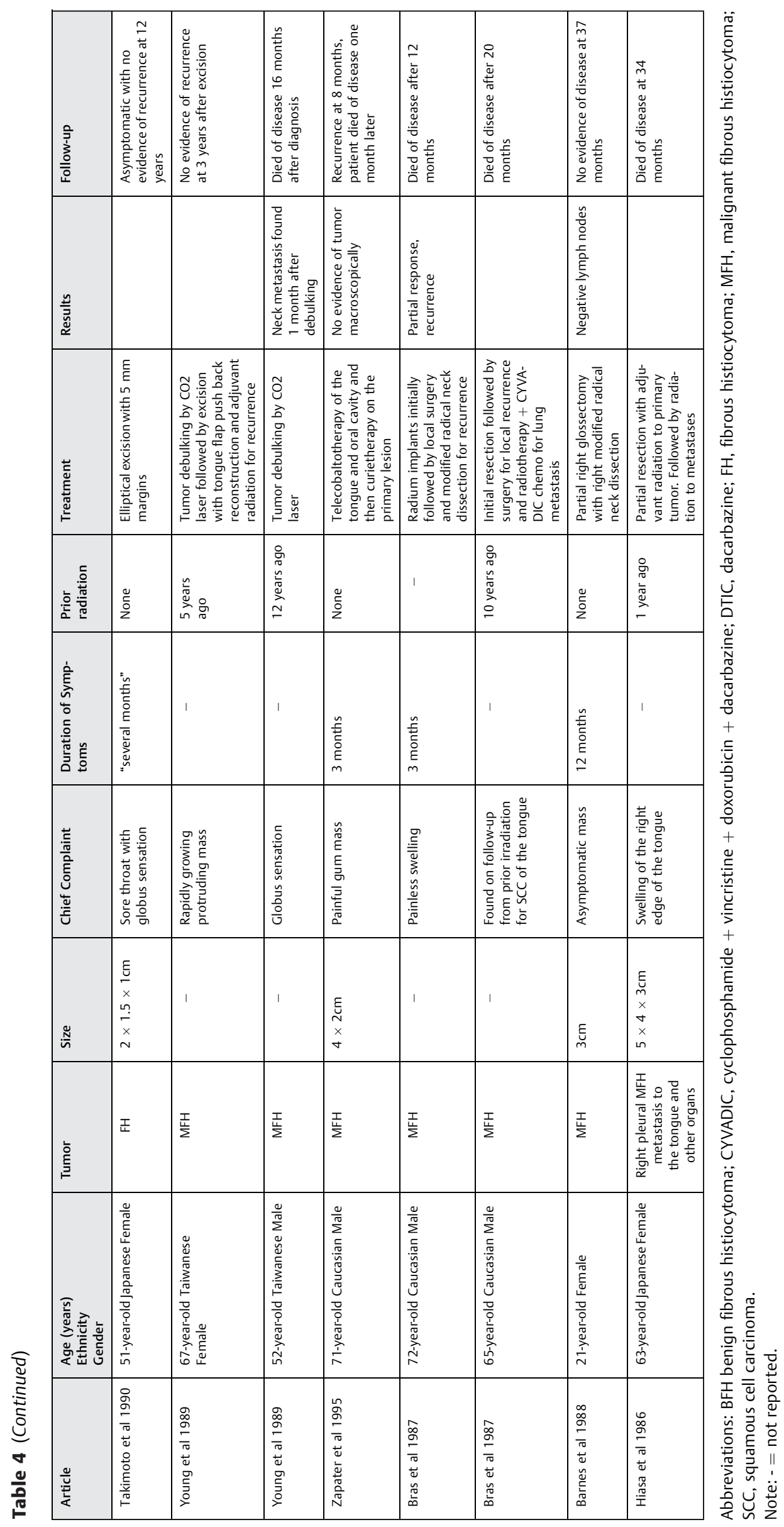




\section{Discussion}

Benign fibrous histiocytomas of the tongue are consistent in clinical presentation and course. The mean patient age is 25.8 years, with $80 \%$ of cases affecting females. The cases presented as painless, gradually growing, firm masses. Surgical excision of benign lesions demonstrated excellent prognosis. The single case using $\mathrm{CO}_{2}$ laser required subsequent hemiglossectomy due to recurrence. In early oral cancers, this modality is potentially an effective and functionally advantageous approach to therapy. ${ }^{30}$ However, in the case of BFH of the tongue, incomplete resection, and thus subsequent recurrence, is of concern. Further study is warranted to validate the efficacy of the $\mathrm{CO}_{2}$ laser as monotherapy for $\mathrm{BFH}$ of the tongue. This modality could also have use in tumor debulking, or may be indicated for smaller lesions.

Accurate histopathological diagnosis of these tumors is critical, considering the large differences in treatment and outcome, based on tumor pathology and, subsequently, malignant potential. The differential diagnosis for $\mathrm{BFH}$ and MFH is broad, and includes the following: fibroma, fibrosarcoma, dermatofibrosarcoma protuberans, neurofibroma, Kaposi sarcoma, among others.

Considering the high innervation, functional importance, and cosmetically sensitive nature of the tongue, tissue-preserving technique could be considered for excision of tumors in this location. Mohs micrographic surgery techniques may be of interest for BFH or MFH of the tongue. A case series of Mohs surgical excision of squamous cell carcinomas affecting the tongue demonstrated promising results, with no recurrence evident at a follow-up of $12-34$ months. ${ }^{31}$ If appropriate, application of this technique could reduce the need for disfiguring glossectomies. Further evaluation of its efficacy is warranted.

The current World Health Organization guidelines for tumors historically called MFH now classifies them as undifferentiated pleomorphic sarcoma. Tumors should be classified as such only after all recognizable lines of differentiation have been excluded. ${ }^{32}$ The nomenclature of MFH subtypes was also changed to the following: storiform-pleomorphic MFH/undifferentiated high-grade pleomorphic sarcoma, giant cell MFH/ undifferentiated pleomorphic sarcoma with giant cells, and inflammatory $\mathrm{MFH} /$ undifferentiated pleomorphic sarcoma with prominent inflammation. These 3 subtypes remained within the "so-called fibrohistiocytic tumors" category, while myxoid MFH/myxofibrosarcoma, now a separate entity, has been moved to the myofibroblastic tumor category. ${ }^{2}$

\section{Final Comments}

The present review of the available literature returned 5 cases of BFH and 15 cases of MFH. The BFH cases demonstrated an apparent predilection for female ( $80.0 \%$ versus $40.0 \%$ in MFH) and younger (25.8 versus 46.6 in MFH) patients than MFH. The benign cases presented as a slowly growing, asymptomatic nodule with a firm, rubbery and elastic texture. The lesions were diagnosed by histopathologic evaluation with immunostaining used primarily for diagnostic exclusion. Of the BFH cases treated with first-line surgical excision, no recurrences were reported, whereas the case treated with initial $\mathrm{CO}_{2}$ laser required subsequent hemiglossectomy for tumor recurrence.

Malignant tumors presented as gray/white, ulcerated, fungating lesions with an average diameter of $2.92 \mathrm{~cm}$. A minority of cases reported physiologic effects of the tumor, including affected tongue motility, dysphagia, hoarseness, and sore throat. The histopathologic workup demonstrated pleomorphic cells with occasional storiform patterns. Mitotic figures were present, with a mix of spindle-shaped fibroblast-like cells, histiocyte-like cells, and multinucleated giant cells. The surgical treatment is first-line, and adjuvant radiotherapy may be considered. Combination chemotherapy regimens vary. Recurrence occurred in $40.0 \%$ of cases (follow-up of 24.1 months), with death due to disease in $46.6 \%$ of patients (follow-up of 19.0 months).

Conflicts of Interest
No conflicts of interest to disclose.

Funding Sources

No funding obtained.

\section{References}

1 LeBoit PE, Burg G, Weedon D, Sarasin A. World Health Organization Classification of Tumours. Pathology and Genetics. Skin Tumours Lyon: IARC Press; 2006

2 Fletcher CDM, Unni KK. World Health Organization Classification of Tumours Pathology and Genetics of Tumours of Soft Tissue and Bone. Cancer 2002;177:1365-76

3 Fletcher CD. Benign fibrous histiocytoma of subcutaneous and deep soft tissue: a clinicopathologic analysis of 21 cases. Am J Surg Pathol 1990;14(09):801-809

4 O'Brien JE, Stout AP. MALIGNANT FIBROUS XANTHOMAS. Cancer 1964; 17:1445-1455

5 Toro JR, Travis LB, Wu HJ, Zhu K, Fletcher CDM, Devesa SS. Incidence patterns of soft tissue sarcomas, regardless of primary site, in the surveillance, epidemiology and end results program, 1978-2001: An analysis of 26,758 cases. Int J Cancer 2006;119(12):2922-2930

6 Marcet S. Atypical fibroxanthoma/malignant fibrous histiocytoma. Dermatol Ther (Heidelb) 2008;21(06):424-427

7 Xi M, Liu MZ, Wang $\mathrm{H}-\mathrm{X}$, et al. Radiation-induced sarcoma in patients with nasopharyngeal carcinoma: a single-institution study. Cancer 2010;116(23):5479-5486

8 Henderson MT, Hollmig ST. Malignant fibrous histiocytoma: changing perceptions and management challenges. J Am Acad Dermatol 2012;67(06):1335-1341

9 Sabesan T, Xuexi W, Yongfa Q, Pingzhang T, Ilankovan V. Malignant fibrous histiocytoma: outcome of tumours in the head and neck compared with those in the trunk and extremities. Br J Oral Maxillofac Surg 2006;44(03):209-212

10 Nascimento AF, Raut CP. Diagnosis and management of pleomorphic sarcomas (so-called "MFH") in adults. J Surg Oncol 2008; 97(04):330-339

11 von Mehren M, Benjamin RS, Bui MM, et al. Soft tissue sarcoma, version 2.2012: featured updates to the NCCN guidelines. J Natl Compr Canc Netw 2012;10(08):951-960

12 Manni JJ, van den Broek P, van Haelst UJ, Slooff JP, Bruaset I. Malignant fibrous histiocytoma of the tongue. J Maxillofac Surg 1986;14(02):103-107 
13 Priya NS, Rao K, Umadevi HS, Smitha T. Benign fibrous histiocytoma of the tongue. Indian J Dent Res 2013;24(05):635-638

14 Chen YK, Lin LM, Lin CC. Malignant fibrous histiocytoma of the tongue. J Laryngol Otol 2001;115(09):763-765

15 Geist J, Azzopardi M, Domanowski A, Plezia R, Venkat H. Thoracic malignant fibrous histiocytoma metastatic to the tongue and skin of the face. Oral Surg Oral Med Oral Pathol 1990;69(02):199-204

16 Lin SK, How SW, Wang JT, Liu BY, Chiang CP. Oral post-radiation malignant fibrous histiocytoma: a clinicopathological study. J Oral Pathol Med 1994;23(07):324-329

17 Mahajan H, Kim EE, Lee YY, Goepfert H. Malignant fibrous histiocytoma of the tongue demonstrated by magnetic resonance imaging. Otolaryngol Head Neck Surg 1989;101(06):704-706

18 McMillan MD, Smillie AC, Ferguson JW. Malignant fibrous histiocytoma of the tongue: report of a case and ultrastructural observations. J Oral Pathol 1986;15(05):255-260

19 Rapidis AD, Andressakis DD, Lagogiannis GA, Douzinas EE. Malignant fibrous histiocytoma of the tongue: review of the literature and report of a case. J Oral Maxillofac Surg 2005;63(04):546-550

20 Restrepo JP, Handler SD, Saull SC, Raney RB Jr. Malignant fibrous histiocytoma. Otolaryngol Head Neck Surg 1987;96(04):362-365

21 Young YH, Hsieh T. Malignant fibrous histiocytoma of the head and neck: report of 5 cases. Taiwan Yi Xue Hui Za Zhi 1989;88(06): 606-609

22 Hiasa Y, Shimoyama T, Kitahori Y, et al. Malignant fibrous histiocytoma with widespread metastasis and pulmonary cancer. Acta Pathol Jpn 1986;36(01):113-122
23 Zapater E, Bagán JV, Campos A, Martorell M, Basterra J. Malignant fibrous histiocytoma of the head and neck. Case report. Bull Group Int Rech Sci Stomatol Odontol 1995;38(3-4):121-124

24 Bras J, Batsakis JG, Luna MA. Malignant fibrous histiocytoma of the oral soft tissues. Oral Surg Oral Med Oral Pathol 1987;64(01):57-67

25 Barnes L, Kanbour A. Malignant fibrous histiocytoma of the head and neck. A report of 12 cases. Arch Otolaryngol Head Neck Surg 1988;114(10):1149-1156

26 López-Jornet P, Camacho-Alonso F, Gómez-García FJ. Oral lesion on dorsum of tongue. J Can Dent Assoc 2011;77:b117

27 Pandey NK, Sharma SK, Banerjee S. A rare case of fibrous histiocytic tumor of the tongue. Indian J Surg 2013;75(01, Suppl 1):1-5

28 Velez-Torres R, Owen LG, Hodge SJ, McMurray GT, Roe E. Atypical fibrous histiocytoma of the tongue. A case report. Int J Dermatol 1986;25(10):656-657

29 Takimoto T, Ishikawa S, Umeda R. Fibrous histiocytoma of the tongue base. Auris Nasus Larynx 1990;16(04):233-236

30 Goodson ML, Thomson PJ. Management of oral carcinoma: benefits of early precancerous intervention. Br J Oral Maxillofac Surg 2011;49(02):88-91

31 Gauthier P, Audet N, Guertin L, et al. Complete frozen section margins (with measurable 1 or $5 \mathrm{~mm}$ thick free margin) for cancer of the tongue: part 2: clinical experience. J Otolaryngol Head Neck Surg 2010;39(01):20-27

32 Jo VY, Fletcher CDM. WHO classification of soft tissue tumours: an update based on the 2013 (4th) edition. Pathology 2014;46(02): 95-104 